\title{
Gramática pulsional: las vicisitudes de la mirada ${ }^{1}$
}

\author{
DANiel FERnÁNDEZ FERnÁNDEZ \\ Instituto de Estudios la Mujer \\ Universidad Nacional, Costa Rica \\ Escuela de Psicología \\ Universidad de Costa Rica
}

\begin{abstract}
Resumen
En este artículo se presentan algunas reflexiones en torno al cuento Las celadas de Narciso, del escritor cubano Frank Padrón, tomando como eje teórico la figura del "amor engañoso", la cual constituye uno de los componentes más destacados del análisis lacaniano en relación con la pulsión escópica. Contrario a una interpretación hermenéutica, se busca, siguiendo un acercamiento barthiano, plasmar algunos efectos significantes que derivan de la lectura del texto, con especial atención en la relación entre el homoerotismo y las vicisitudes de la mirada.
\end{abstract}

Palabras claves: pulsión escópica, cuerpo, imagen, deseo, homoerotismo

\section{Abstract}

This article presents some reflections around the story Las celadas de Narciso by the Cuban writer Frank Padrón, taking as a theoretical axis the notion of "deceitful love", one of the most salient components of the lacanian analysis about the scopic drive. Contrary to a hermeneutical interpretation, the objective of this work, following a barthian approach, is to capture some significant effects, derived from the reading of the text, making a special emphasis on the relation between homoerotism and the vicissitudes of the glance.

Key words: scopic drive, body, image, desire, homoerotism

\section{Résumé}

Dans cet article on présente quelques réflexions par rapport au comte Las celadas de Narciso, de l'écrivain cubain Frank Padrón, en prenant comme axe théorique la figure de "l'amour trompeur", qui constitue un des composants les plus saillants de l'analytique lacanienne concernant la pulsion scopique. Contrairement à une interprétation herméneutique, on cherche, en partant d'un point de vue barthien, à capturer quelques effets signifiants dérivés de la lecture du texte, en faisant une emphase particulière dans le rapport entre l'homoérotisme et les vicissitudes du regard.

Mots clés: pulsion scopique, corps, image, regard, homoérotisme 


\section{Preludio visual}

Por una mirada, un mundo; por una sonrisa, un cielo; por un beso... ¡Yo no sé qué te diera por un beso! Gustavo Adolfo Bécquer (Rima XXIII)

$\mathrm{E}$ n consonancia con una de esas habituales inquietudes barthianas, es válido asentir que desde hace siglos nos hemos interesado de manera desmedida por el autor y absolutamente nada por el lector, "lo que se trata de establecer siempre es lo que el autor ha querido decir, y en ningún caso lo que el lector entiende" (Barthes, 2009, p. 41). Nos ocupamos aquí de una tesitura, o quizá convenga decir texitura, en el sentido de un textolector, pues siguiendo a Barthes, si la composición de la escritura tiende a canalizar, la lectura por su parte tiende a dispersar, a diseminar; al leer "hay, de manera inmediata, un suplemento de sentido del que ni el diccionario ni la gramática pueden dar cuenta" (p.41).

En el presente artículo me dispongo a llevar a cabo el análisis de un texto, con el cual no pretendo descubrir el sentido oculto que ha llevado a su autor a escribir su obra, ni mucho menos interrogar el sentido de su decir, sino más bien, captar el espacio de suplemento de mi lectura, al que ha de agregarse una diseminación más, pues la iniciativa para desarrollar este escrito responde a la incitativa que provocó mi lectura del libro L'amour Lacan, del psicoanalista Jean Allouch.

Antes de hacer referencia al texto -en sentido restricto- que dará lugar al presente artículo, quiero hacer una breve mención a la antología en la que este es compendiado, es decir, al libro no como un epicentro literario, sino al libro en lo que respecta a su apariencia exterior, a la materialidad de la forma, a lo que concisamente revelan los atributos gráficos de su portada.

Durante un viaje a Cuba, visité la Librería Universitaria, un pequeño aposento ubicado al pie de una apoteósica escalinata llamada Alma Mater (¿esta disposición no es acaso un reflejo apodíctico del discurso universitario?). Estando ahí, mientras revisaba los múltiples estantes que regurgitaban política, revolución y algunas nostalgias, mi mirada se desvió a la portada algo oscura y borrosa de un libro en el que parecía dibujarse un seno, coronado por un pezón no menos difuso.

Ante lo inusitado de este hallazgo, me acerqué para verificar mi impresión inicial, corroborando así que no consistiera en uno de esos típicos espejismos lascivos, que bien podríamos llamar (re) lapsus visual. El allanamiento óptico confirmó los primeros indicios, pues efectivamente se trataba de la imagen de un busto desnudo que aparecía en la tapa del libro, al cual se yuxtapone un esmoquin apenas esbozado, como se muestran en la imagen que aparece en la figura 1.

La reseña de la contratapa parecía confirmar que este texto era un delegado solitario en aquel atril de libros: "El sentir gay, el cuerpo homosexual, la feminidad lésbica, la mirada homoerótica, el intercambio queer, las relaciones entre maricas, chicos straight, locas, tuercas, bisexuales, transexuales, drags, travestis y otras variaciones". El índice, por su parte, invitaba a lecturas tan sugerentes como "Factor sorpresa", "La amante de lady Chatterley" o "Situaciones violentas, personajes infames y blúmer rosa". 
Figura 1

Portada del libro

Instrucciones para cruzar el espejo

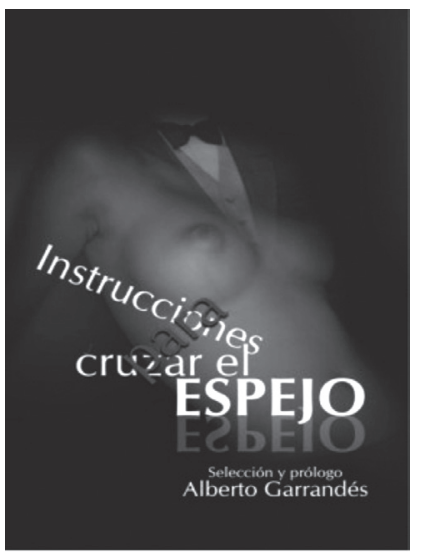

En esta rápida prospección, me percaté de que en uno de los títulos aparecía el nombre de Narciso. El título que leí en ese momento y por el cual decidí a mi regreso acudir a esta antología, se intitulaba Las celdas de Narciso, de un autor cubano llamado Frank Padrón (1958). Mi sorpresa posterior fue que el título del cuento no era aquel que yo había supuesto, no se trataba de "celdas" sino más bien de "celadas", y por la tanto el título correcto correspondía a Las celadas de Narciso.

Bajo términos morfológicos laxos la diferencia no pareciera ser tan significativa, se trata de la elisión de una $a$, una $a$ comida, una $a$ ausente, una $a$ que es ausencia. Ahora bien, en términos semánticos entre celdas y celadas parece haber una diferencia importante. La Real Academia de la Lengua Española nos dice que una celda se refiere a "Cada uno de los aposentos donde se encierra a los presos en las cárceles celulares", mientras que para celada encontramos la siguiente acepción: "Engaño o fraude dispuesto con artificio o disimulo".
Tenemos, por tanto, a un Narciso en dos escenas muy diferentes, en la primera podría suponerse que la celda de Narciso es aquella en la que este se encuentra encarcelado, una versión quizá más cercana a la tragedia griega, Narciso preso en su auto-obnubilación. Otra versión de esta primera escena podría ser aquella en la que Narciso en vez de tener una posición pasiva en la que es encerrado, dispondría -dado que se trata de la celda de Narciso-, de un fuero especial sobre ese aposento celular, sería por tanto un espacio a su cargo, lo cual nos daría por resultado a Narciso el carcelero y el narcisismo como su ley. Finalmente en la segunda escena, en la escena celada (en este caso por la elisión incurrida), se abren otras dos vías elucubrativas en función de la preposición de, que replican en otra esfera la misma disyuntiva: ¿Se trataría entonces de los engaños perpetrados por Narciso o hacia él?

Esta y otras preguntas que se puedan dirigir a cualquiera de las escenas antes reseñadas, no aspiran a encontrar una respuesta por vía de las intelecciones lingüísticas, no buscan ser tampoco el objeto de hermenéutica alguna, ni tan siquiera pretenden tomar el texto como "testimonio" o "ejemplo paradigmático de...", que otorgue un sentido de verdad. "Lo que me gusta de un relato no es directamente su contenido ni su estructura sino más bien las rasgaduras que le impongo a su bella envoltura." (Barthes, 2008, p.19).

De esta forma, lo que persigo con la evocación de este equívoco visual que vacila con el destino de Narciso, es precisamente introducir -a partir de la impostura de quien lee-, una discusión en torno a una de las figuras de l'amour Lacan, concernida de manera 
preponderante por el campo de la función escópica, a saber, el amor engañoso (l'amour trompeur). Un simple traspié, una en apariencia, banal imprecisión de lectura, es precisamente lo que $d a$ pie a una lectura que procura captar cierta instancia de deseo, la cual no podría tener lugar si no es por la intervención de este fallo. Tanto la texitura como el amor se prestan gozosamente al engaño, ya sea que se trate del objeto de aquel que ama o del que lee, la incursión transitiva de cualquiera de estos sujetos (hasta el momento tácitos), requiere de una determinada obcecación de los sentidos, ¿no es acaso de esto de lo que trata el placer del texto?

\section{Pulsión escópica}

La experiencia amorosa une indisolublemente lo simbólico (lo prohibido, discernible, pensable), lo imaginario (lo que el Yo representa para sustentarse y agradarse) y lo real (ese imposible donde los afectos aspiran a todo y donde no hay nadie que tenga en cuenta el hecho de que no soy más que una parte)

(Kristeva, 2004, p. 6).

Existe un conocido adagio popular que dice que "todo entra por la mirada". Para atender el valor de este conocido dicho, se requiere pensar en qué consiste este "todo" y qué es aquello que se dice que "entra". El cuento de Frank Padrón inicia poniendo en juego la incidencia de esta sentencia. El texto se abre de la siguiente manera: "Iba caminando distraído de regreso a casa cuando de pronto, recostado a una baranda de la calle Línea, se encontró consigo mismo." (Padrón, 2010, p. 279).
Prosigue diciendo:

$\mathrm{Al}$ principio apartó la vista, lo atribuyó a una de esas trastadas de la retina que nos hacen ver literalmente visiones, sobre todo de noche, pero cuando se fijó bien ya no hubo lugar a dudas. Se trataba de él, una auténtica imagen y más que un doble, porque era idéntico, y no una de esas personas que simplemente se nos parecen. (Padrón, 2010, p. 279).

Incluso sus nombres eran casi el mismo, el personaje principal, llamado Alex, no pudo más que quedar sorprendido al descubrir que el nombre de su interlocutor especular difería del suyo únicamente por la disposición de algunas letras, pues se trataba de Axel. Al yuxtaponer Alex y Axel, nos damos cuenta de que, exceptuando la letra "A", tenemos una perfecta lectura en espejo, cual preludio a este encuentro con un sí mismo ajeno.

A medida que transcurría la escena, Alex iba descubriendo las múltiples afinidades que existían entre ambos y comenzaba a sentir una atracción que para él resultaba verdaderamente inusitada, pues:

[...] aun cuando al mirarse al espejo se veía atractivo, y disfrutaba como el que más contemplándose recién afeitado y elegante, distaba mucho de "desearse", de "estar enamorado de sí mismo" o todas esas bagatelas. Le gustaba gustar, sí, a las mujeres, pues era plenamente hetero y nunca había sentido la mínima atracción por hombre alguno, incluyéndose él, y he aquí que alguien tan similar (al punto de estar casi convencido de que era él mismo de alguna manera), le arrancaba una peligrosa 
llamada a su libido. (Padrón, 2010, pp. 280-281)

Lacan describe el funcionamiento de la pulsión escópica tomando como recurso la metáfora pictórica. "Lacan présente alors une théorie selon laquelle, dans le rapport du peintre et de l'amateur, le tableau est un trompel'œil" (Allouch, 2000, párr. 220) ${ }^{2}$, zanjando así una analogía entre la relación pictórica y la relación amorosa. El aficionado será engañado como será engañado el amante. Alex, como todo un neófito de la pintura homoerótica, queda embelesado ante aquel cuadro exhibido cual galería en la Calle Línea. Queda cautivado por la belleza de un hombre, un Adonis que era él mismo:

A medida que iban avanzado, Alex se sentía más confundido y a la vez más encantado; ya no era simple impresión: le gustaba aquel hombre. Él no era homofóbico, uno de esos que critica y ataca a los gays, pero nunca le habían interesado. [...] veía en la calle jóvenes tan femeninos y bellos como mujeres (o quizá más), pero nunca le habían hecho volver la vista. No se explicaba entonces que le atraía en este hombre tan parecido a sí mismo, cuando ni siquiera predominaba en él la feminidad. (Padrón, 2010, p. 281)

Como señala Lacan, "desde un principio, en la dialéctica del ojo y la mirada vemos que no hay coincidencia alguna, sino un verdadero efecto de señuelo" (2012, p. 109). Y en este punto resulta pertinente preguntarse ¿por qué un señuelo?, ¿qué hay ahí de engaño?, ¿cómo atender el carácter de esta disquisición ocular? Como señala Allouch, "le tableau est offert non au regard mais à l'œil et -précision décisive- à l'œil comme organe" (2000, párr. 221) ${ }^{3}$. Aquello por lo cual Alex se ve súbitamente confundido y encantado, está dado por un recorte orgánico. La pintura satisface el ojo como órgano, no la pulsión escópica que es por tanto lo que, a través de él, busca su satisfacción. Esta precisión es la que marca un distanciamiento entre el psicoanálisis y el enfoque psiquiátrico de la sexualidad, pues en la acera de las gabachas, pulsión y objeto están indisolublemente ligados, haciendo plausible la naturalización de la heterosexualidad.

Para el psicoanálisis existe una disyunción de la pulsión y su objeto; Axel no es el objeto al que Alex dirige -como si se tratara de un juego de puntería- su pulsión. Lacan zanjará las particularidades de esta distinción en la sesión del 13 de mayo de 1964, al plantear que la pulsión puede alcanzar su satisfacción sin alcanzar su fin. Para ello dirá que lo que ocupa el lugar de un fin o una meta en esta ecuación, tiene dos sentidos que se explican con claridad, y toma como recurso la lengua inglesa:

Aim: si se encarga a alguien una misión, aim no se refiere a lo que ha de traernos, se refiere al camino que tiene que recorrer. The aim es el trayecto. La meta tiene también otra forma, the goal. Goal, en el tiro al arco, no es tampoco el blanco, no es el pájaro que derribamos, es, más bien, haber marcado un punto y, con ello, haber alcanzado la meta. (Lacan, 2012, p. 186)

Aquel encuentro suponía sin duda la apertura de un nuevo recorrido para Alex, la antesala a una misión desconocida; 
Alex está ansioso por tirar al arco y marcar un punto en una operación un tanto bizarra, pues el blanco parece más bien un gris, una superficie extimia, valga decir, dos pájaros de un tiro. Pero recordemos que lo medular aquí no es tanto el blanco en sí, sino más bien marcar un punto. A este propósito, Lacan desarrolla en este mismo Seminario lo que denomina la teoría del circuito pulsional. Señala que dicho circuito está estructurado por las tres voces gramaticales y toma como referente para dar cuenta de ello la pulsión escópica:

\section{Voz activa: ver}

Voz reflexiva: verse

Voz pasiva: ser visto

Repasemos la escena de contemplación que se desarrolla en la espontánea galería de aquella calle cubana, teniendo en cuenta ahora estos giros gramaticales. A las claras podemos decir que el gesto de Alex lo inscribe gramaticalmente en el giro de la voz activa, Alex ve. No obstante, la complejidad de la escena está dada por el carácter reflexivo de la mirada, Alex se ve, pero no viéndose a sí mismo, sino viendo a un otro, lo que por derivación trastoca el sentido de la voz pasiva, aquel en el que se supone que emerge un sujeto, Alex es visto, pero no por un otro, sino por él mismo. Lo anterior convierte a Alex en un tirador al cual podemos calificar como inmerso en varias vicisitudes ¿Cómo marcar un punto cuando el blanco es tan incierto? Y ¿cómo puntuar cuando el blanco es, de alguna forma, él mismo?

La construcción de esta escena posiciona el carácter limítrofe de la pulsión que ya Freud enunciaba:
Si ahora, desde el aspecto biológico, pasamos a la consideración de vida anímica, la "pulsión" nos aparece como un concepto fronterizo entre lo anímico y lo somático, como un representante [repräsentant] psíquico de los estímulos que provienen del interior del cuerpo y alcanzan el alma, como una medida de la exigencia de trabajo que es impuesta a lo anímico a consecuencia de su trabazón con lo corporal. (Freud, 1915, p. 121)

A partir de esta proximidad límite entre lo anímico y lo somático, Lacan signa la interfaz del ojo y la mirada en el nivel de la pulsión escópica. No obstante, dicha adyacencia no conlleva una formación estable, sino más bien un espectro alegórico que prefigura las voces gramaticales en el decurso de la mirada. Como señala Teresa de Lauretis (2010), la pulsión es un espacio o "localidad psíquica", que no solo es no-homogéneo, sino más precisamente, heterotópico: es un espacio de tránsito, un desplazamiento, pasaje y transformación -no un espacio referencial, sino figurativo-. (Lauretis, 2010)

La mirada de Alex describe así una trayectoria gramaticalmente polimorfa y socialmente perversa. Comporta una disyunción de dos metarrealidades $^{4}$ intrínsecamente referidas entre sí, como las que conllevan las antípodas de alto - bajo, derecho - izquierdo, femenino - masculino, homosexual heterosexual, yo - otro, erastés - erómenos, realidades que ocupan -como bien señala Lauretis-, localidades psíquicas sí, pero de ninguna forma ancladas al suelo de la inmanencia biológica. Se presenta aquí una disquisición que tiene que ver precisamente con la disyunción entre pulsión y objeto, un arreglo que podría resumirse 
en la siguiente fórmula lacaniana: "Je t'aime, mais parce que j'aime inexplicablement quelque chose en toi plus que toi" (Allouch, 2000, párr. 224) ${ }^{5}$.

\section{Cuerpo e imagen}

El ser hablante aprehende su cuerpo como imaginario: una envoltura, como una bolsa, análoga a un traje. (Morel, 2002, p. 80)

Hasta ahora nos hemos centrado en ese primer encuentro especular que inauguraba para Alex la desconocida senda del homoerotismo. Posterior a esa delectación inicial de la mirada y al correspondiente flirteo, los personajes deciden llevar esta espontánea atracción a otros términos. Una vez estando en el apartamento de Alex, transcurre la siguiente escena:

(...) se había creado una atmósfera de grata sensualidad, pero Alex no estaba seguro de cómo romper el hielo en el caso de un hombre. Incluso, tenía dudas sobre si el recién conocido era gay, si se ofendería, digamos, al invitarlo a bailar, lo que por otra parte le parecía tan ridículo. Al parecer, Axel no tenía el mismo criterio, pues se le adelantó.

-¿Bailamos?

No sólo no se molestó cuando el otro comenzó a llevarlo en la danza como el hombre, sino que hasta sintió placer cuando este le acarició sutilmente las nalgas, y poco después, al besarlo primero con ternura y enseguida con fuerza, prosiguió aquel su inalterable papel masculino, al que Alex se abandonaba cada vez más sin esfuerzo, con delectación.

(...)
Dejaron de bailar cuando el anfitrión, apartándose un poco, se quitó la camisa; su invitado lo imitó, pero lo hizo con lentitud, disfrutándolo a la manera de un strip-tease. Alex sintió entonces la misma sensación de incredulidad inmediatamente desmentida por la evidencia que había experimentado al conocerlo, al encontrarse en él (con él) recostado a la barandilla de la calle Línea, pues al despojarse Axel de su ancha camisa descubrió dos pequeños pechos de mujer. Axel sonrió, y con el mismo gesto placenteramente teatral se soltó el pelo, se arrancó súbito el bigote postizo, al que le siguieron ahora lentos el pantalón, el calzoncillo, las medias y los zapatos también de hombre, hasta quedar completamente desnudo, desnuda.

-Me llamo Verónica -agregó, mientras se acomodaba en un amplio sofá-cama imitando a la maja desnuda. (Padrón, 2010, pp.282-283).

Esta escena conlleva el redoblamiento de una vicisitud pulsional, pues concediendo el relato desde su concepción, el valor de un coup de foudre, es decir, de ese flechazo instantáneo que captura a Alex en la calle Línea, es indudable que en esa relación especular con el cuerpo, se juega también algo en relación con el amor. A este respecto, Lacan plantea que: "lo que hay bajo el hábito y que llamamos cuerpo, quizá no es más ese resto que llamo objeto a. Lo que hace que la imagen se mantenga es un resto." (Lacan, 2008: 321). En el relato que nos ocupa, de lo que se trata es precisamente de imagen, de un efecto imaginario sobre el cuerpo, en el que se produce una corporalidad recortada, que conlleva efectos significantes. "Ce corps de l'autre avec lequel 
on baise, il y a lieu de l'imaginer recouvert ici et là de quelques étiquettes porteuses, chacune d'un signifiant, de ces signifiants même qui règlent le déroulement de l'acte sexuel." ${ }^{\text {(Allouch, }}$ 2000, párr. 294).

Alex, el prototipo habanero de un donjuán, se ve ahora delectado con un i(a), es decir con una imagen que convoca la causa de su deseo (llamémosle deseo inconsciente, apellidémoslo enclosetado), en la que una geografía corporal hasta ahora inexplorada, se vuelve objeto de fascinación y éxtasis. Cual orografía especular, las condiciones de posibilidad que le permiten a Alex (habitual geógrafo heterosexual donjuanesco) hacer estos primeros estudios de suelo, están directamente relacionadas con la imagen de sí, con una determinada figuración del yo. Siguiendo a Bersani (1986), el yo (the ego) no es solo, en la topografía mental de Freud, la parte del aparato mental más directamente influenciada por el contacto del cuerpo con el mundo, es también una proyección mental de las superficies corpóreas.

\section{La maja sorprende a Alex}

El escenario homoerótico que Alex iba vislumbrando en cada nuevo acercamiento con Axel, sufre un revés, el relato alcanza su acmé con una imagen bastante evocativa (figura 2).

Se pasa súbitamente de un misterioso Adonis a una diáfana maja desnuda. En este momento, la consternación se apoderó de Alex, quien pensaba que aquello se trataba de alguna broma, como si hubiese habido un plan previo de imitarlo y provocar aquel encuentro. La "repentina" huésped, para calmarlo, le dice:

Soy actriz de un proyecto teatral nuevo llamado Mascarada. Desde niña adoro el travestismo, la simulación: mi vida son los disfraces, incluso fuera del escenario, como ya sabes, cualesquiera que sean, pero sobre todo los de hombre. (Padrón, 2010, p. 284).

Alex no podía salir del estado de obnubilación en el que lo había dejado, cual escena primaria, la repentina

Figura 2

Francisco de Goya (1746-1828), La maja desnuda, Madrid, Museo del Prado

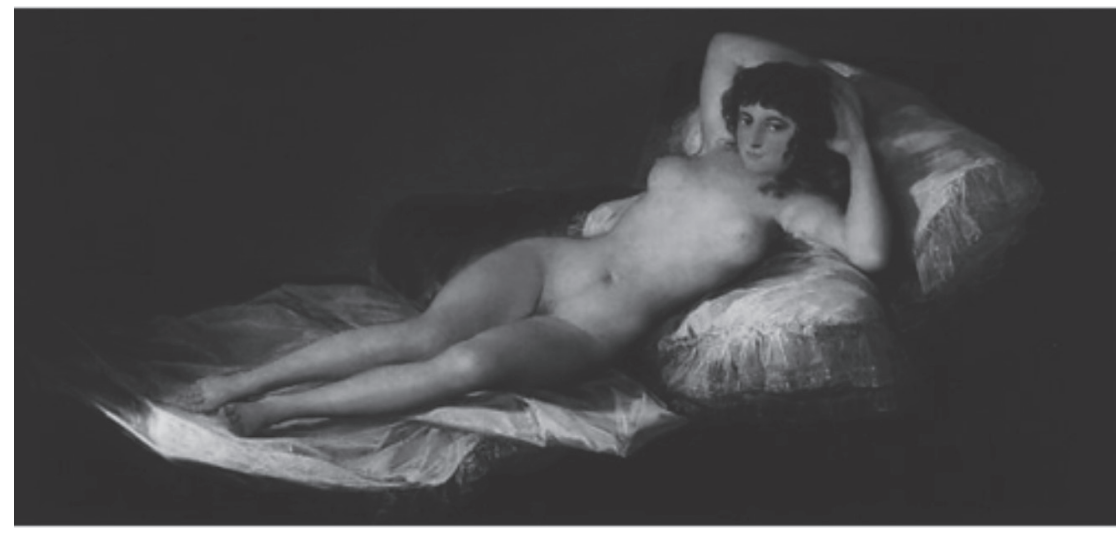


diferencia sexual. Después de algunos intentos más de apaciguamiento, su acompañante le dice:

$-¿$ No terminas lo que empezamos?

Él respondió como sacudiéndose de una hipnosis:

-Creo que no puedo, lo siento.

-¿Así que ibas a poder, estabas pudiendo a la perfección mientras me imaginaste hombre aun cuando ni siquiera, según tú, eres bisexual, y ahora no, cuando se supone que estás en tu elemento?

-Pero imagínate, después de esta maraña que ni sé por dónde empezar a desenredar...

-That is the question, dear. No el to be or not to be, Hamlet exageraba. (Padrón, 2010, p. 285).

Posteriormente a una discusión con parámetros más o menos similares, el corto relato llega al final, sin que Alex pudiera llevar a buen fin aquello que inicialmente era causa de su deseo: "[Alex] no pudo, por primera vez en su vida, hacer el amor, a pesar de que era hermosa, como él, porque era él con otro sexo, o con dos sexos, vaya usted a saber. Era todo tan enrevesado y oscuro que terminaba por lanzarlo de nuevo al mundo del inconsciente". (Padrón, 2010, p. 286).

Alex a pesar de estar, como señala su repentina interlocutora, en su "elemento", no puede "hacer el amor". ¿Cómo entender este desenlace sin hacer psicología del personaje o del autor? Esta pregunta, heredera de la Clínica Clásica de la cual hablaba Foucault, "no hace más que hacer circular la mirada médica bajo un movimiento autónomo, es decir, a través de una circularidad que se controla a sí misma”.
(Foucault, 2001: 55). Pero, ¿cómo soslayar entonces dicha Clínica?, ¿Cómo entender esta detumescencia frente a ese cuadro que reflejaba tanta belleza? Mi apuesta como lector es la siguiente: mediante otro cuadro y mediante otra lectura que corresponde respectivamente al cuadro Psique sorprende Amore y la lectura del comentario que desarrolla Lacan de este. De acuerdo con Allouch (2000), Lacan trae a colación esta pintura en un momento decisivo de su enseñanza en lo que concierne al falo. Dos elementos resultan pertinentes para el análisis de esta "constipación del deseo" en Alex: la fenomenología del mito y la composición del cuadro.

Figura 3

Jacopo del Zucchi (1590), Psiche sorprende a Amore, Roma, Galería Borghèse

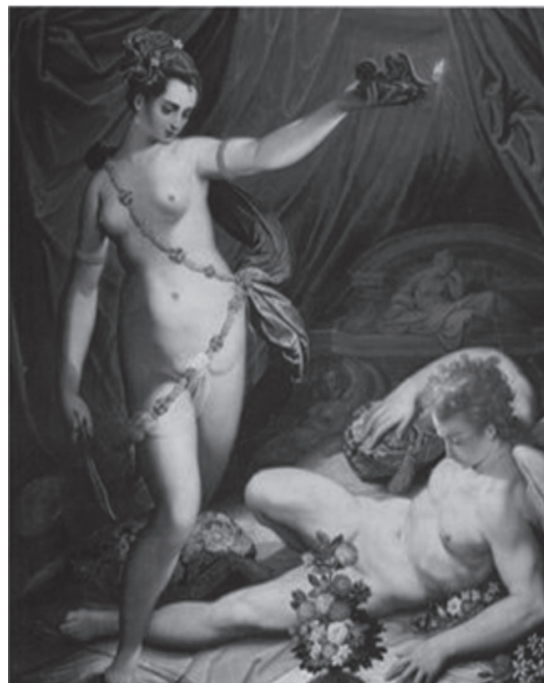

Lacan señala que se trata de la escena clásica de Psique alzando su pequeña lámpara sobre Eros, que desde hace bastante tiempo es su amante nocturno nunca percibido 7 . Psique, favorecida por un extraordinario amor, el del propio Eros, goza de una felicidad 
que podría ser perfecta si no le asaltara la curiosidad de ver de quién se trata y aunque Eros no ha podido decirle cuál sería la sanción resultante, su insistencia en permanecer invisible es extrema; no obstante, Psique no puede evitarlo y en ese instante empiezan sus desgracias (Lacan, 2004, p. 253).

La sintaxis del deseo (es decir, la forma en que se unen los distintos elementos que lo conforman) que presenta el mito de Eros y Psique, tiene un equivalente gramatical contemporáneo: el cuarto oscuro. Según Bersani, el barebacking gang-bang (orgías consensuadas con gente desconocida sin protección), constituye un laboratorio en el cual la viabilidad de los impulsos y fantasías condenadas como inviables por la autocensura son puestos a prueba a partir de la viabilidad que presupone dicho espacio (Bersani, 2011). ¿No es la oscuridad que envuelve a Eros la que lo hace tan deseable y la que tanto favorece la felicidad de Psique? ¿y no es acaso el carácter seductoramente enigmático de Axel la causa del deseo de Alex? Siguiendo a Barthes:

Todo el mundo puede testimoniar que el placer del texto no es seguro: nada nos dice que el mismo texto nos gustará por segunda vez; es un placer que fácilmente se disuelve, se disgrega por el humor, el hábito, la circunstancia, es un placer precario (obtenido gracias a una plegaria silenciosa dirigida a las Ganas de sentirse bien y que estas Ganas pueden revocar) [...]. El goce del texto no es precario, es peor, es precoz; no se produce en el tiempo justo, no depende de ninguna maduración. Todo se realiza de una vez y este arrebato es evidente en la pintura actual: desde el momento en que es comprendida el principio de la pérdida se vuelve ineficaz, es necesario pasar a otra cosa. Todo se juega, se goza, en la primera mirada. (Barthes, 2008, p.84)

Es precisamente a partir de esta digresión barthiana en torno a la no alternancia entre el placer y el goce textual, que nos disponemos a argüir que la negativa de Alex -una vez situado en su elemento- se yergue sobre una relación concomitante; si los buenos prolegómenos no fueron garantía para la consumación del tan esperado arrebato paroxístico, es justamente porque la mirada, o mejor dicho, la inmensa incertidumbre que de ella descuella, es la que comanda el rumbo del deseo. En la escena que se comienza a desarrollar en la calle Línea, la mirada/lectura de Alex convierte a Axel en un agente de goce y por tanto no queda lugar alguno para el placer. A guisa de conclusión, retomaremos esta conjetura a partir de la lectura de Lacan sobre el cuadro de Zucchi en el siguiente y último apartado.

\section{Trazos finales de lectura}

\section{It didn't occur to anybody to assign a symbol to the absence of objects.} (Seife, 2000, p. 8)

En la gramática del cuarto oscuro -esa misma que excita a Psique desde hace tiempo y que envuelve a Alex en el preámbulo de la iniciación- (Halperin, 2001), el accionar de los actuantes es eminentemente intransitivo, su ejecución al no requerir de ningún tipo de complementariedad obligatoria vuelve admisible lo inadmisible; co $(\mathrm{n} / \mathrm{m})$ placer supone un acto narcisista que requiere del concurso de un suplemento siempre 
tácito pero permutable, en otros términos, hablamos de un placer taci-turno. Pensado en su dimensión copulativa, la opacidad en la que tiene lugar el goce, hace que ser quien se es (o quien se cree ser: to be or not to be) no tenga ninguna importancia, de tal manera que la enunciación de la forma intransitiva del yo gozo pasa a configurar un yo soy gozo, generándose así una conjunción en la que sujeto y predicado se desdibujan.

Figura 4

Énfasis de la imagen de Jacopo del Zucchi (1590), Psiche sorprende a Amore, Roma, Galería Borghèse

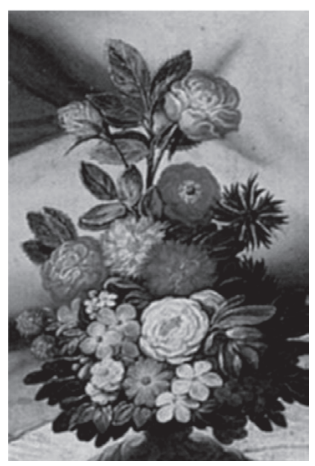

En términos de composición, y este es el aspecto que más impacta a Lacan, la obra de Zucchi está revestida de un particular interés en lo que se refiere a esta escena en la que Psique decide querer ver. El florero que aparece en el primer plano es para Lacan el punto óptico más destacado, "el centro mental visual del cuadro" (Lacan, 2004, p. 254), el punctum de Roland Barthes, de tal forma que enfocar equivale aquí a cogitar, o lo que es lo mismo, el cogito, ergo sum pasa a ser un zoom, ergo cogito.

La ubicación de las flores conlleva un carácter disruptivo, genera un efecto de extrañeza, como si fuese un elemento exógeno que parece recordar ese recurso tecnológico empleado en la televisión para censurar determinadas imágenes, en las que se pixela o se recorta la parte considerada como obscena ${ }^{8}$. No obstante, y contrario a este razonamiento, según Allouch, para Lacan las flores del cuadro no esconden el falo de Eros, sino su ausencia. "Qu'il n'y ait rien derrière ces fleurs, c'est précisément par là que Lacan rend hommage au peintre d'avoir «porté» le phallus manquant «a la majeure signifiance»" (Allouch, 2000, párr. 178) ${ }^{9}$.

Para Psique, el florero no simboliza la presencia velada del falo, sino su ausencia, sustento imaginario de su deseo, caso distinto del de Alex, en el que el falo pierde su estatus significante, pues el desvelamiento de la maja, contrario a signar la simbolización de su ausencia imaginaria, sanciona su presencia. En ambas escenas, de lo que se trata es precisamente de la portación del falo, que no está referido en absoluto a un aspecto de carácter anatómico:

[...] el falo accede al estatuto de objeto petit $a$ en tanto que falta. Esto no es en absoluto evidente. $\mathrm{E}$ incluso puede contrariar el sentido común, la opinión según la cual no hay cogida si el falo falta. Por cierto, eso no es falso. No hay cogida sin falóforo, sin un portador del falo, ya sea ese portador anatómicamente hombre o mujer (puesto que, como ustedes saben, el falo no es solamente lo que se presenta, en su magnificencia, en la forma del pene en erección, puede ser un látigo, un niño, mil cosas más. Mediante las cuales una anatomía de mujer puede perfectamente funcionar como falófora). (Allouch, 2000, párr. 23-24). 
De acuerdo con el planteamiento de Allouch, se puede afirmar que la conservación del símbolo que supone ser falo, constituye un aspecto que se ubica incluso por encima del deseo. En el cuadro de Zucchi, Psique sorprende a Eros quien se encuentra dormido; por su parte, en el relato de Padrón, la maja (Verónica) sorprende a Alex, y es precisamente ahí donde podemos ubicar la celada, en una gramática pulsional que conjugaba su narcisismo y por ende su homoerotismo; para Alex, el falóforo es Axel.

Si en la orgía anónima prender la luz equivale a poner fin al erotismo, es precisamente porque reconocer(se) equivale a poner coto a la inconmensurabilidad del imaginario, a las imágenes táctiles, sonoras, gustativas, a la figuración de físicos que no se ven, en otras palabras, a la aleatoriedad del falo; para Alex, la cruda belleza de la maja tendida en el sofá-cama equivale a un interruptor del deseo, no porque esa corporalidad le resulte excitablemente ajena, sino porque no correspondía con el cuerpo embelesado de su imaginario, ese mismo que fue hilvanado lentamente en el deleite de lo ambiguo; dicho en otros términos, el falo se prescentifica.

Así, concluiremos diciendo que para Alex el homoerotismo constituye el micro-cuarto-oscuro de su deseo, el falóforo que habita su imaginario, y con ello arriesgaremos aquí otro neologismo, la mirada -y no lo que se mira: the aim- se vuelve un "faróforo". Los faros fungen como señales para indicar a los navegantes cómo llegar a lugares que de otra manera no podrían ser vistos, lugares que para muchos marineros bien podrían ser completamente desconocidos y cuyo arribo no queda resuel- to con el avistamiento de aquella señal, pues su detección es solo principio de un proceso en el que las posibilidades de encallar son bastante altas. Llevar el deseo a buen puerto no equivale a tratar de alcanzar la luz del faro, pues como es bien sabido, debajo de los faros no existe ningún puerto...

\section{Notas}

1 Una primera versión de este texto fue presentada inicialmente bajo el título "Cuerpo, Imagen y Pulsión" en el marco del Dispositivo de Lectura: L'amour Lacan: "Baile con él", organizado por la École Lacanienne de Psychanalyse en el Instituto Cultural de México en San José, Costa Rica, el día 26 de mayo de 2012.

2 "Lacan desarrolla una teoría según la cual, en la relación del pintor y el aficionado, el cuadro es una engañifa".

3 "(...) el cuadro está dispuesto no a la mirada, sino al ojo -y precisión decisiva-al ojo como órgano".

4 Según Allouch, no hay realidad (una realidad distinguida por Lacan de lo real), hay solamente juicios de realidad, los cuales ponen en juego su implicación (Allouch, 2000, párr. 298). El prefijo meta en este sentido señala este carácter subjetivo, al tiempo que enfatiza el planteamiento lacaniano en torno a la "satisfacción" de la meta pulsional.

5 "(...) yo te amo, porque amo inexplicablemente algo en ti más que a ti".

6 "Ese cuerpo del otro con el cual se coge, hay lugar para imaginarlo recubierto aquí y allá de algunas etiquetas, portadoras cada una de un significante, de esos mismos significantes que regulan el desarrollo del acto sexual".

7 El motivo del cuadro de Zucchi es la obra El asno de oro, de Apuleyo. 
8 El arte parece no ser ajeno a este recurso, es así como en el año 2012 se organizó una exposición de arte renacentista en el Museo Nacional de China, en ocasión de la apertura de un ala del museo que había estado en restauración. Una de las obras más destacadas de dicha exposición fue el David-Apolo de Miguel Ángel, mostrada con los genitales pixelados en un reportaje realizado por la televisión nacional china. ¿Este episodio no es quizá una de las formas modernas más acabadas para conducir la genitalidad al estatus del falo?

9 "Que no haya nada detrás de esas flores, es precisamente como Lacan rinde homenaje al pintor por haber «llevado» el falo faltante «a la mayor significancia»".

\section{Bibliografía}

Allouch, J. (abril, 2000). Cuando el falo falta... Conferencia dictada en la Universidad de Córdoba. [htm]. En: http://www.con-versiones.com. ar/nota0482.htm [Consultado el 8 de octubre del 2014].

Allouch, J. (2009). L'amour Lacan. París: Epel.

Barthes, R. (2008). El placer del texto y lección inaugural. Buenos Aires: Siglo Veintiuno Editores.

Barthes, R. (2009). El susurro del lenguaje. Más allá de la palabra y la escritura. Barcelona: Paidós.

Bécquer, J.-A. (1994). Rimas, leyendas y narraciones. México: Editorial Porrúa.

Bersani, L. (1986). The Freudian Body. Psychoanalysis and Art. Nueva York: Columbia University Press.

Bersani, L. (2011). Shame on you. In: Halley, J. y Parker, A. (Comp.) After Sex? On writing since queer theory. Durham y Londres: Duke University Press.

Foucault, M. (2001). El nacimiento de la clínica. Una arqueología de la mirada médica. Buenos Aires: Siglo Veintiuno Editores.

Freud, S. (1915). Pulsiones y destinos de pulsión. Obras Completas. Volumen XVI, Buenos Aires y Madrid: Amorrortu.

Halperin, D. (junio, 2001). Iniciación. Revista Litoral, Las comunidades electivas. II. Espacios para el erotismo, École Lacanienne de Psychanalyse. Córdoba: Ediciones Literales, $\mathrm{N}^{\mathrm{o}} 31$, pp. 91-114.

Kristeva, J. (2004). Historias de amor. Coyoacán: Siglo Veintiuno Editores. Lacan, J. (2012). Los cuatro conceptos fundamentales del psicoanálisis. El Seminario de Jacques Lacan. Texto establecido por Jacques-Allain Miller. Buenos Aires: Ediciones Paidós. Lacan, J. (2004). La transferencia. El Seminario de Jacques Lacan. Texto establecido por Jacques-Allain Miller. Buenos Aires: Ediciones Paidós.

Lacan, J. (2008). Aun. El Seminario de Jacques Lacan. Texto establecido por Jacques-Allain Miller. Buenos Aires: Ediciones Paidós.

Lauretis, T. de (2010). Freud's drive. Psychoanalysis, literature and film. Nueva York: Palgrave y Macmillan. Morel, G. (2002). Ambigüedades sexuales. Sexuación y psicosis. Buenos Aires: Manantial.

Padrón, F. (2010). Las celadas de Narciso. En Alberto Garrandés, Instrucciones para cruzar el espejo. La Habana: Editorial Extramuros.

Seife, C. (2000). Zero. The Biography of a Dangerous Idea. Nueva York: Penguin Books. 
